\title{
ARM Processor Based Vehicle Theft Detection System
}

\author{
Padmanabhan Subbulakshmi ${ }^{1}$, MCharan Tej ${ }^{2}$, M Manojsreenivas Reddy $^{3}$ \\ ${ }^{1}$ PD-Eng-Platform(Department), StubHub, San Francisco, CA-94105. \\ ${ }^{2,3}$ School of mechanical and building science, VIT Chennai, India
}

\section{ABSTRACT}

The theft in vehicle ratio has increased rapidly in recent days. Due to this reason there is demand in manufacturers of automobile over safety of the vehicles. Several processor have been reported in developing anti theft system recommended to developing antitheft system.The control of car is implemented using finger print scanning. A laser diode and photo detector is placed at all window glass preventing the vehicle from breaking of glass and entering inside the vehicle and a vibration sensor is placed at the engine to prevent from vehicle getting started without access of the finger print, in case any chance the engine starts the sensor detect the vibration and immediately blocks the fuel supply and alert the owner by sending a SMS through GSM and send the coordinate of car using GPSmodule.

Keywords: Vehicle Security System, Advanced RISC Machine (ARM) Processor, Finger print Recognition, Vibration sensor, Laser diode and photo detector, Ultrasonicsensor

\section{INTRODUCTION}

In the recent years lot of work has been carried out in Display innovation in vehicle. Burglaries can happen in any place on the planet from urban to provincial range. So to maintain a strategic distance from this issue a substitute arrangement has been taken like against robbery framework. It is a gadget to evade or stop the issue. Considerable steps have been taken in the recent years to overcome these problems by providing authorization to ownerabuilt in anti theftsystem.

\section{LITERATURE SURVEY}

Real time vehicle theft identity and control system based on ARM7 was done by I Anup Kamat in this paper they used ARM7 processor for the prevention of vehicle theft using face recognition. Real time vehicle theft identity and control system based on ARN9 was done by Ms Radhika.D in this paper they done prevention of vehicle theft using face recognition by taking ARM9 processor. ARM9 based realtime control and vehicle theft identity system was done by Ms Radhika. D in this paper they done prevention of vehicle theft using face recognition using camera by using ARM9processer.

\section{OBJECTIVE}

The main objective of our study is to develop a smart anti theft system with incorporating authorization to owner.Interfacing Ultrasonic sensor, vibration sensor, laser diode, GSM and GPS module with ARM processer. 


\section{METHODOLOGY}

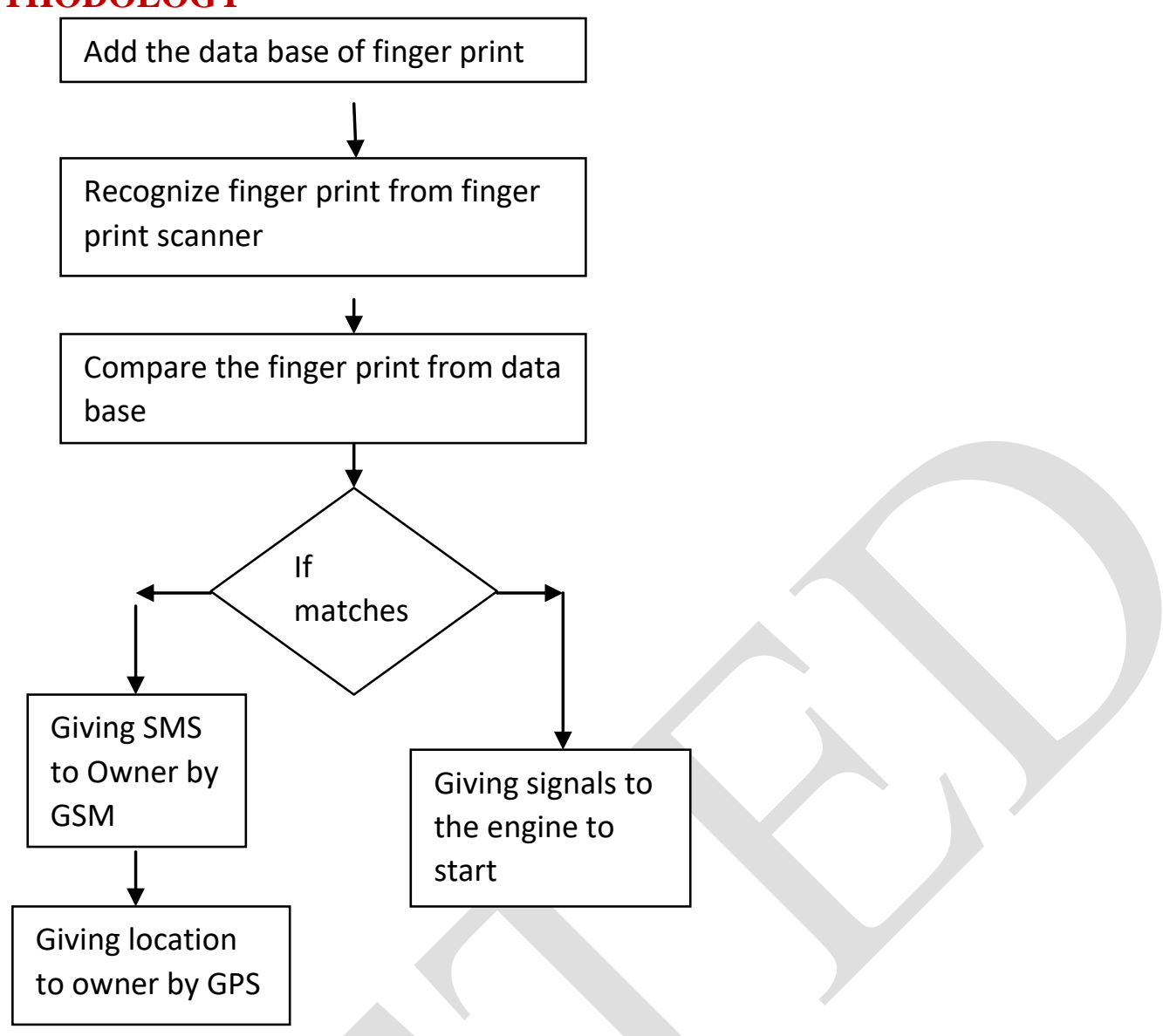

\section{COMPONENTS OF THE PROPOSED SYSTEM}

Present work implements an anti-theft system from burglary utilizing ARM (Advanced RISC machine) processor. So by utilizing unique mark Recognition frame work individual finger can be distinguished. In the event that the unique finger impression does not match then the coordinate willbesent to the user via SMS and area of vehicle utilization through GSM and GPS module.

\section{PROBLEMSTATEMENT}

Now a days there is an high level of theft. There is more safety for driver life like keeping air bag, regenerative breaking system etc. But there is no safety for car. The first problem is that breaking of glass. There may be a chance to break the glass to steal the car so, we are using laser diode and photo detector to prevent. Second problem is that steeling the car without key so, we are using two sensor over here they are finger print sensor and vibration sensor. Without access of finger print sensor they cannot start engine if they start also we used vibration sensor at the engine so, the information is sent to owner.

\section{GSM}

GSM is nothing but global system for mobile communication. The wireless port of GSM is connected to the computer by using this we can receive and send the message. GSM vehicle tracking system is mainly used to capture the location data. 


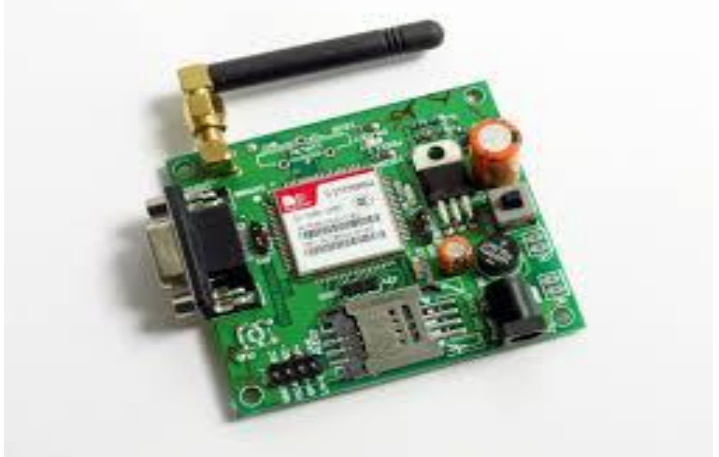

Figure 1.GSM module.

GPS

GPS is nothing but global position system and it is used for navigation system. The positions from the three satellite is given to the triangulates, that position is appeared in geographical position nothing but latitude and longitude. There is an accuracy of GPS is 10 to 100 meters.

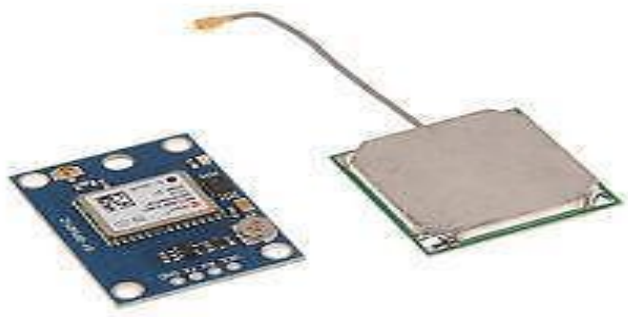

Figure 2.GPS module.

\section{FINGER PRINT SENSOR}

Finger print sensor is a biometric operation which is interfaced to the microcontroller and to a PC through MAV 232/USB- serial adapter. Using biometric finger print we can access control, safety deposit box etc. Finger print recognition is a method that match the human prints. Finger print consists of two things, one is finger print enrolment and other one isfinger print matching. The finger print matching can be 1:1 or $1: \mathrm{N}$. The generated template is compared with the templates of the finger library. If $1: \mathrm{N}$ matches, the system search in the finger library and gets the matching finger. If 1:1 matches, the live finger compares with the specific template. The authentication of finger print is recorded twice in finger print enrolment. The templates of the finger will be generated.

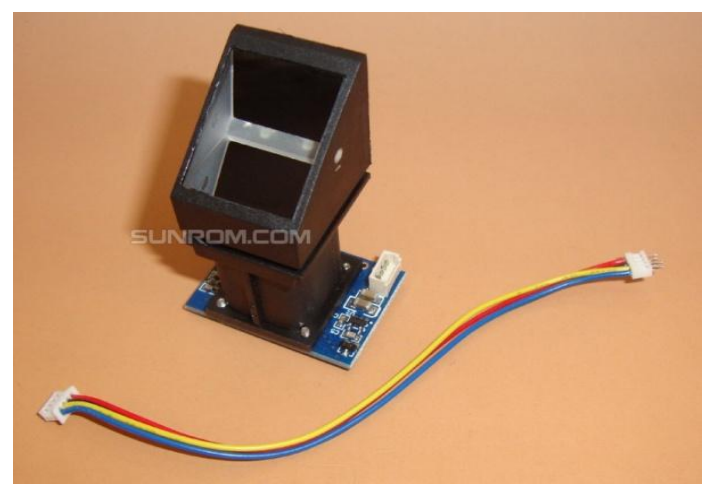

Figure 3. Fingerprint sensor 


\section{ARM DUE}

It is 32 bit microcontroller and based on RISC architecture and optimized for low power and performance versatile express board with cortex -A9 core will be emulated using Linaro builds.

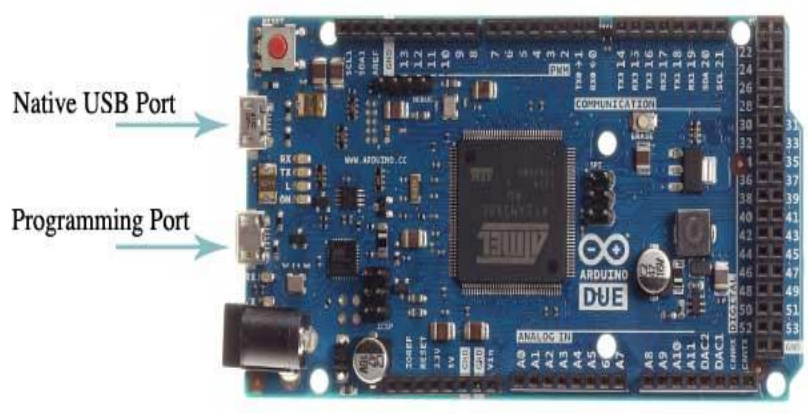

Figure 4.ARMDUE PROCESSOR.

\section{VIBRATION SENSOR}

The vibration sensor detects the vibration in the system. The relay module is compared with the normal vibration sensor module. If there is vibration the vibration trigger will on and this will be used in theft alarm, earthquake alarm, motorcycle alarm etc. When there is no vibration in the system, the LED will be in switched off the $\mathrm{o} / \mathrm{p}$ is high. When there is vibration in the system, the LED will switched off and the $\mathrm{o} / \mathrm{p}$ is low. The output is connected to the microcontroller with the help of the microcontroller to detect the $\mathrm{o} / \mathrm{p}$ high or low.

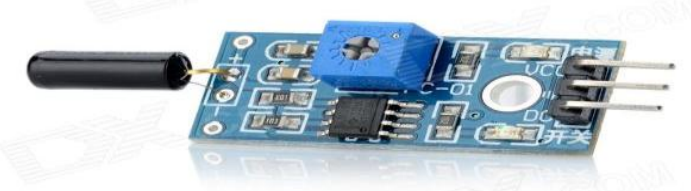

Figure 5.VIBRATION SENSOR.

\section{ULTRASONIC SENSOR}

Ultrasonic sensor is most popularly used as well as low cost module. For this sensor having a range from very short to long range for detection.

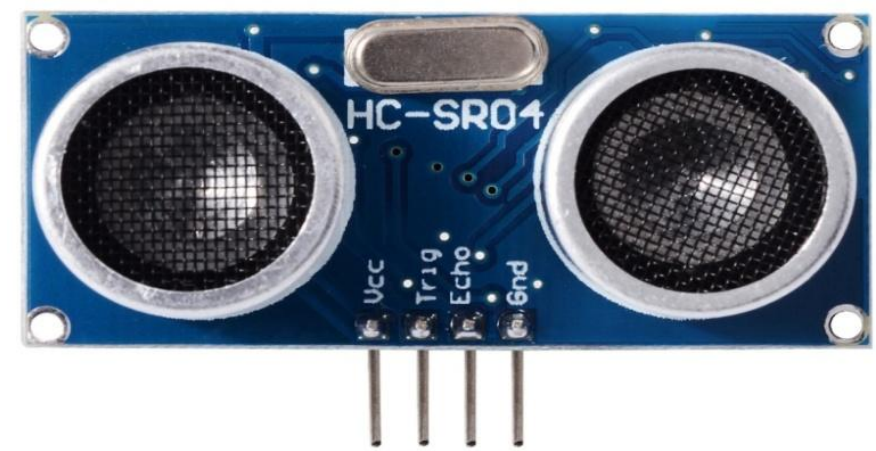

Figure 5. ULTASONIC SENSOR 


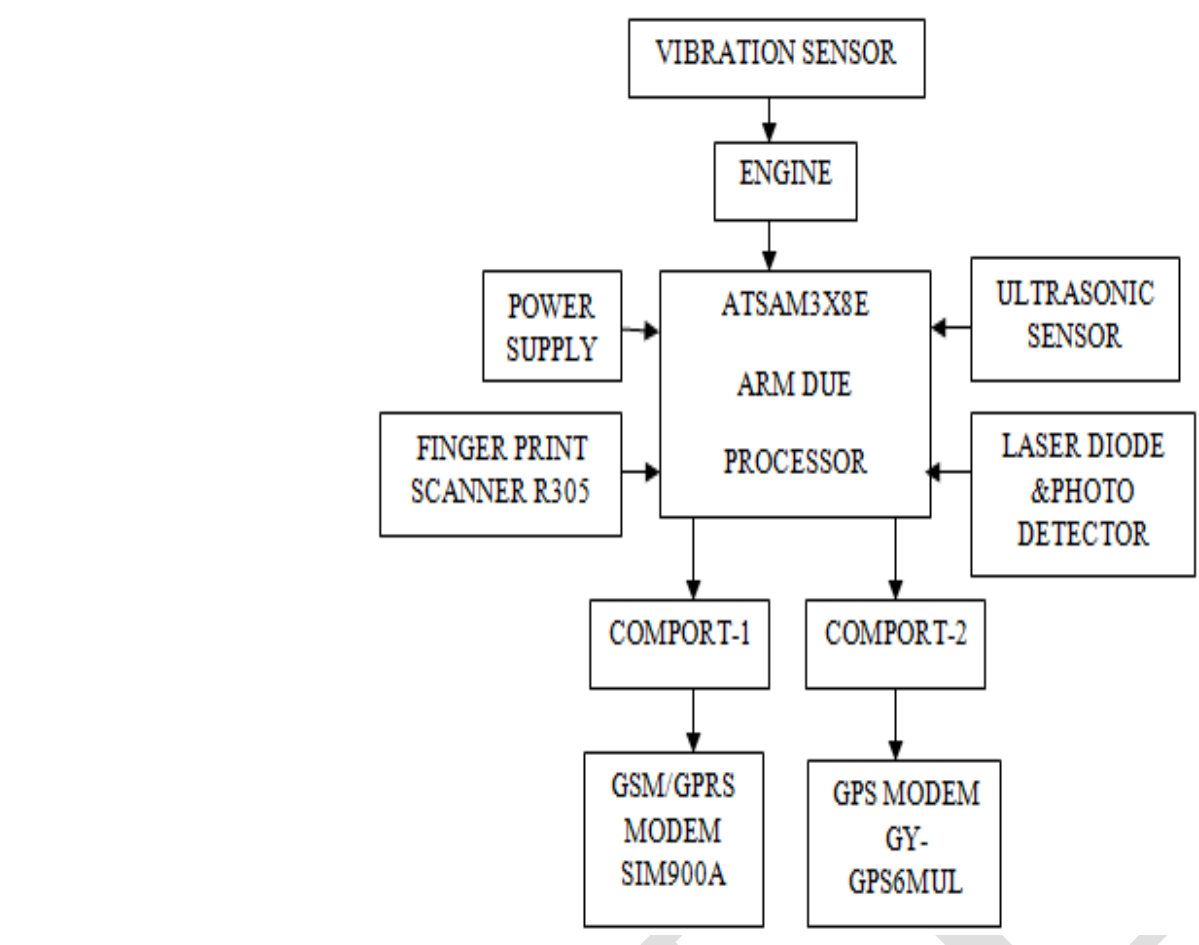

\section{METHODOLOGY}

Finger print sensor is placed at steering wheel and it can be accessed only by the authorized owner whose finger print is saved into the data base if any individual other than the approve individual attempt to get to the vehicle then it will caution the proprietor by sending SMS and coordinates of vehicle through GPS and GSM system. Vibration sensor is placed at the engine suppose a person is trying to access the car without the access of finger print recognization then due vibration occurred at the engine and it will detect and alert the owner and a laser diode and photo detector is used at the all door window glasses when any person break the glass then there will be stop in passage of light and it will alert the owner sending the SMS and coordinates of car by using GSM and GPS system.

\section{EXPERIMENTAL SETUP}

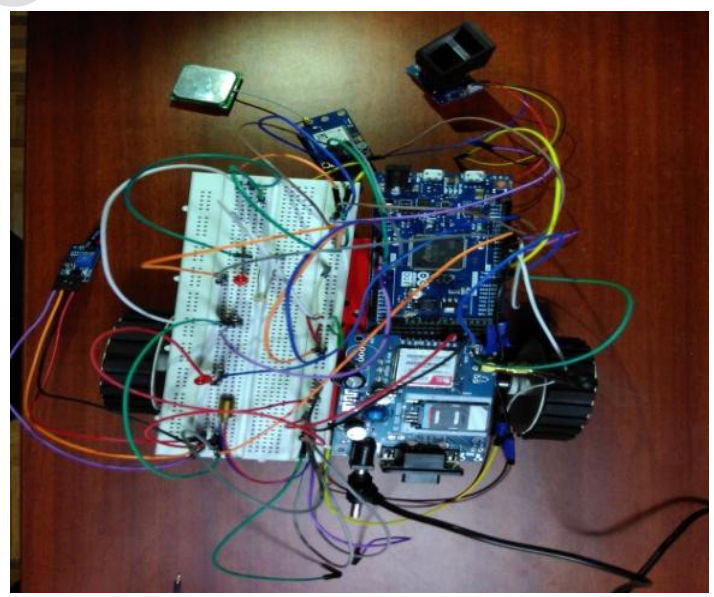




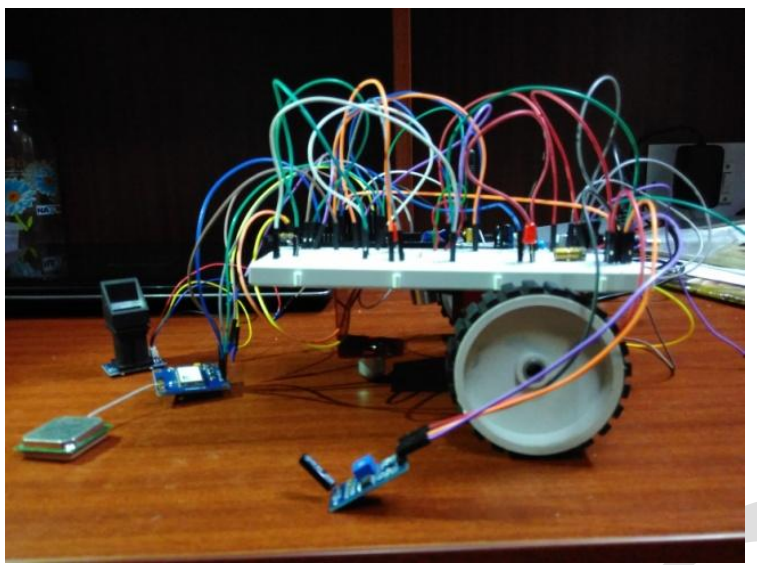

\section{CONCLUSION}

We designed and tested vehicle anti-theft system based on ARM DUE processor was successful. Finger print recognition is advantage for the prevention of vehicle theft. Finger print recognition has been found to working well. In the present work the finger print sensor take the data base of the owner' finger. Vehicle will not start if any other person want to start because there is no data base on the finger print sensor. In this present work we can give multiple data base to the finger print sensor. Vibration sensor on the engine and laser diode and photo resistor on the vehicle window has been used for the prevention and gives information or indication to the owner.

\section{REFERENCES}

- Arun Sasi1, Lakshmi R Nair2 'Vehicle Anti-Theft System Based On An Embedded Platform" IJRET, pISSN: 2321-7308

- Ms. Radhika D. Rathi1, Prof. Ashish Mulajkar2, Badhe3' Real Time Vehicle Theft Identity And Control System Based On ARM 9", Volume 2 , Issue 1(Jan-Feb 2015), PP 731-736

- Weiping Chen and YongshengGao' A Minutiae-based Fingerprint Matching Algorithm Using Phase Correlation", IAnupKamat, IISonaliDevtarse, IIIS.R.Nibe' Real Time Vehicle Theft Identity and Control System Based on ARM 7' IJARET, Vol. 2, Issue 1 (Jan. - Mar. 2015).

- Ganesh G.S.P, Balaji B and Varadhan T.A.S, "Anti-theft tracking system for Automobiles", IEEE International Conference on Anti-Counterfeiting, Security and Identification (ASID), pp. 17-19, 2011.

- Sadagopan V.K, Rajendran U and Francis A.J, "Anti-theft Control System design using Embedded System", IEEE International Conference on Vehicular Electronics and Safety (ICVES), pp. 1-5, 2011. 